\title{
Jaboticaba peel and jaboticaba peel aqueous extract shows in vitro and in vivo antioxidant properties in obesity model
}

\author{
Sabrina Alves Lenquiste ${ }^{\mathrm{a}, *}$, Rafaela da Silva Marineli ${ }^{\mathrm{a}}$, Érica Aguiar Moraes ${ }^{\mathrm{a}}$, Ana Paula Dionísio ${ }^{\mathrm{b}}$, \\ Edy Sousa de Brito ${ }^{\mathrm{b}}$, Mário Roberto Maróstica Junior ${ }^{\mathrm{a}}$ \\ a Department of Food and Nutrition (DEPAN), Faculty of Food Engineering (FEA), University of Campinas (UNICAMP), Campinas, SP, Brazil \\ ${ }^{\mathrm{b}}$ Embrapa Tropical Agroindustry, Fortaleza, CE, Brazil
}

\section{A R T I C L E I N F O}

\section{Article history:}

Received 17 April 2015

Received in revised form 8 July 2015

Accepted 15 July 2015

Available online 17 July 2015

\section{Keywords:}

Myrciaria Jaboticaba (Vell.) Berg

Obesity

Oxidative stress

Antioxidant enzymes

Lipid peroxidation

\begin{abstract}
A B S T R A C T
This study evaluated the chemical composition of freeze-dried jaboticaba peel (FJP) and jaboticaba peel aqueous extract (JE) and their antioxidant capacity in vitro and in vivo in obesity model. Phenolic compounds, total anthocyanins, flavonoids and antioxidant capacity (DPPH, FRAP, ABTS and ORAC assays) in FJP methanolic extract and JE were measured. Specific phenolics (ellagic and gallic acids) and anthocyanin (cyanidin-3-O-glucoside) were measured by LC-DAD-ESI/MS. In the biological assay thirty-six Wistar rats were divided in six groups: AIN$93 \mathrm{M}$ normal control diet; HFF (obese control) feed a high-fat and fructose diet; Prevention FJP (P. FJP) and Treatment FJP (T. FJP) feed HFF diet with 2\% of FJP powder, for 12 and 6 weeks respectively; Prevention JE (P. JE) and Treatment JE (T.JE) were feed with HFF diet and the water was substituted by JE, for 12 and 6 weeks, respectively. FRAP, TBARS, GSH and antioxidant enzymes (GPX, GR, CAT and SOD) were determined in the plasma and liver. The limit of significance was set at $P<0.05$. The FJP methanolic extract showed higher levels of total phenolics and anthocyanins, ellagic acid and DPPH, FRAP and ORAC assay, but JE showed higher levels of cyanidin-3-0-glucoside, gallic acid and ABTS assay. Antioxidant potential of the FJP and JE were confirmed by important markers in animals, such as TBARS and GSH levels and CAT activity, but not by FRAP assay, and SOD, GR and GPx enzymes. Thus, FJP and JE showed an important antioxidant effect in vitro and in vivo.
\end{abstract}

(c) 2015 Elsevier Ltd. All rights reserved.

\section{Introduction}

Excessive production of reactive oxygen species (ROS) is identified as one of the key mechanisms in the development of obesity and other metabolic disorders such as insulin resistance (IR) and diabetes (Ando \& Fujita, 2009; Feillet-Coudray, Sutra, Fouret, et al., 2009). The excess of reactive species can damage cell lipids, proteins and DNA by oxidative action, which might result in loss of function and even cellular death (Habib \& Ibrahim, 2011), which has linked the oxidative stress to some diseases (Durackova, 2010).

Studies have shown that hypercaloric/high-fat diets can induce oxidative stress and metabolic disorders in obesity induced animal model by excessive production of reactive species and decrease in the antioxidant protection (Aschbachera, Kornfeldc, Picardd, et al., 2014; Tsuchiya, Ebataa, Sakabeb, Hamaa, Kogurea, \& Shiota, 2013). The combat against oxidative damage is endogenously mediated by enzymatic antioxidant system, compound for the enzymes superoxide dismutase (SOD), glutathione reductase (GR), glutathione peroxidase (GPx) and catalase (CAT), and non-enzymatic systems: thiol reduced (GSH), vitamins, minerals and polyphenols (Rezaie, Parker, \& Abdollahi, 2007).

\footnotetext{
* Corresponding author.

E-mail address: sabrina_nutri28@yahoo.com.br (S.A. Lenquiste).
}

Nutritional alternatives to counteract the oxidative damage are necessary, in order to avoid the appearance and progression of obesity and chronic diseases. The role of phytochemicals in the oxidative damage combat it has been studied (Habib \& Ibrahim, 2011; Han, Shen, \& Lou, 2007). Phenolic compounds are the principal class of dietary phytochemical, naturally present in plant foods, especially fruits, and have important antioxidant potential/capacity (Prior, Wilkes, Rogers, Khanal, Wu, \& Howard , 2010).

The jaboticaba (Myrciaria Jaboticaba (Vell.) Berg), a Brazilian typical fruit, has high nutritional value. Mainly, jaboticaba peel has a significant content of minerals, soluble and insoluble fiber, and phenolic compounds (Alezandro, Dubé, Desjardins, Lajolo, \& Genovese, 2013a; Alezandro, Granato, \& Genovese, 2013b; Lima, Duarte, Carvalho, Patto, \& Dantas-Barros, 2008). Leite, Malta, Riccio, Eberlin, Pastore, \& Marostica (2011) identified cyanidin-3-O-glucoside and delphinidin3-O-glucoside as predominant anthocyanins in freeze-dried jaboticaba peel. In addition to anthocyanins, jaboticaba peel has high concentrations of tannins, gallic acid and ellagic acid that have important antioxidant effect (Abe, Lajolo, \& Genovese, 2012; Wu, Dastmalchi, Long, \& Kennelly, 2012; Wu, Long, \& Kennelly, 2013).

Due to high bioactive compounds concentration, the in vitro and in vivo antioxidant potential of jaboticaba peel has been reported by several authors (Alezandro, Dubé, Desjardins, Lajolo, \& Genovese, 
2013a; Alezandro, Granato, \& Genovese, 2013b; Batista, Lenquiste, Cazarin, et al., 2014; Leite, Malta, Riccio, Eberlin, Pastore, \& Marostica, 2011). In these studies, the jaboticaba peel showed elevated values of DPPH, FRAP, ABTS and ORAC assays, as well increases GSH and antioxidant enzymes in animal model. Thus, the objective of present study was to identify and quantify the bioactive compounds in the freeze-dried jaboticaba peel (FJP) and in the FJP aqueous extract (JE) and to evaluate their antioxidant capacity by in vitro assays. Furthermore, we evaluated the antioxidant potential of the FJP and JE supplementation in animals with oxidative stress induced by high fat and high fructose diet.

\section{Methods}

\subsection{Preparation of freeze-dried jaboticaba peel (FJP)}

Jaboticabas (M. Jaboticaba (Vell.) Berg) were acquired in Campinas Central Supply (CEASA), Brazil. Fruits were selected and cleaned. The peels were manually separated and were frozen, freeze-dried and milled to get a homogeneous powder. The powder was stored at $-80{ }^{\circ} \mathrm{C}$ in dark flasks, prior to analysis and preparation for the in vivo assays.

\subsection{Proximate centesimal composition of FJP}

Analyses of humidity, total protein and ash were performed according to methods described by Association of Official Analytical Chemists (AOAC, 2002). Total lipids were determined by Bligh \& Dyer (1959). Soluble and insoluble fibers were determinate according to Asp, Johansson, Hallmer, \& Siljestrom (1983). Carbohydrate content was obtained by difference using the equation: $100-$ (moisture + protein + lipid + ash + dietary fiber) and energy value was determined in isoperibol automatic calorimeter (PARR 1261) with oxygen pump (PARR 1108).

\subsection{FJP extracts preparation}

FJP MeOH extract was prepared mixing $0.5 \mathrm{~g}$ of FJP powder with $12.5 \mathrm{~mL}$ of $\mathrm{MeOH}: \mathrm{H} 2 \mathrm{O}$ (70:30) (v/v). After vortex-mixing, sample was sonicated for $10 \mathrm{~min}$. Extracts were filtered on paper filter and reextracted twice. Filtrates were mixed and filtered again on $0.45 \mu \mathrm{m}$ filter. FJP aqueous extract (JE) were obtained by weighing $2.0 \mathrm{~g}$ FJP powder and $100 \mathrm{~mL}$ boiling water addition. The extract was maintained in infusion for $30 \mathrm{~min}$ and manually homogenized each $15 \mathrm{~min}$. Afterward extract was filtered under vacuum pressure and stored at $4{ }^{\circ} \mathrm{C}$ until analysis.

For phenolic LC-DAD-ESI/MS analysis FJP powder (1.0 g) was mixed with $15 \mathrm{~mL}$ of MeOH:H2O:Acetic acid (85:15:0.5) (v/v), vortex-mixed for $30 \mathrm{~s}$ and sonicated for $5 \mathrm{~min}$. Samples were vortex-mixing for $30 \mathrm{~s}$, two times, until complete $10 \mathrm{~min}$. Samples were centrifuged at $3500 \mathrm{rpm}$ for $10 \mathrm{~min}$ at $25{ }^{\circ} \mathrm{C}$. The extraction process was repeated with $10 \mathrm{~mL}$ of the solution. Thereafter, extracts were combined and diluted to $25 \mathrm{~mL}$ with the same solvent. All samples were filtered through $0.45 \mu \mathrm{m}$ filter. HPLC analyses used the same aqueous extract as described above. Extracts were prepared in triplicate for all analyses.

\subsection{Total phenolic determination}

Total phenolic content was determined using the Folin-Ciocalteau method as described by Singleton, Orthofer, and Lamuela-Raventos (1999). Samples and a gallic acid standard curve were read at $725 \mathrm{~nm}$. Results were expressed as mg gallic acid equivalent $\mathrm{g}^{-1}$ or $\mathrm{mL}^{-1}$. Total flavonoid concentration was quantified using the colorimetric method described by Herald, Gadgil, \& Tilley (2012). Samples and catechin standard curve were read at $510 \mathrm{~nm}$. Results were expressed as $\mathrm{mg}$ catechin equivalent $\mathrm{g}^{-1}$ or $\mathrm{mL}^{-1}$. Total anthocyanin concentration was performed by the $\mathrm{pH}$ differential method described by Fuleki \& Francis
(1968), with some modifications. The samples were read at 300 and $700 \mathrm{~nm}$. Results were expressed as $\mathrm{mg} 100 \mathrm{~g}$ or $\mathrm{mL}^{-1}$. Assays were performed in triplicate for all samples.

\subsection{Phenolic compounds analysis by LC-DAD-ESI/MS}

Cyanidin-3-0-glucoside identification and quantification was performed according to general procedure for screening of phenolics in plant materials with modifications (Lin \& Harnly, 2007). LC-DAD-ESI/ MS instrument consisted of a Varian 250 HPLC (Varian, CA) coupled with a diode array detector (DAD) and a 500-MS IT mass spectrometer (Varian, CA). A Symetry C18 (Varian Inc., Lake Forest, CA) column $(3 \mu \mathrm{m}$, $250 \times 2 \mathrm{~mm}$ ) was used at a flow rate of $0.4 \mathrm{ml} \mathrm{min}^{-1}$. The column oven temperature was set at $30^{\circ} \mathrm{C}$. Mobile phase consisted of a combination of $\mathrm{A}(0.1 \%$ formic acid in water) and B ( $0.1 \%$ formic acid in acetonitrile). Gradient was varied linearly from $10 \%$ to $26 \%$ B (v/v) in $40 \mathrm{~min}$, to $65 \%$ B at $70 \mathrm{~min}$, and finally to $100 \% \mathrm{~B}$ at $71 \mathrm{~min}$ and held at $100 \% \mathrm{~B}$ to $75 \mathrm{~min}$. The DAD was set at 270 and $512 \mathrm{~nm}$ for real-time read-out and UV/VIS spectra, from 190 to $650 \mathrm{~nm}$, were continuously collected. Mass spectra were simultaneously acquired using electrospray ionization in the positive and negative ionization modes ( $\mathrm{PI}$ and $\mathrm{NI}$ ) at a fragmentation voltage of $80 \mathrm{~V}$ for the mass range of 100-1000 amu. A drying gas pressure of $35 \mathrm{psi}$, nebulizer gas pressure of $40 \mathrm{psi}$, a drying gas temperature of $370{ }^{\circ} \mathrm{C}$, capillary voltages of $3500 \mathrm{~V}$ for PI and $3500 \mathrm{~V}$ for NI, and spray shield voltages of $600 \mathrm{~V}$ were used. LC system was coupled to the MSD with a splitting of $50 \%$. Results were expressed as $\mu \mathrm{g} \mathrm{g}^{-1}$ or $\mathrm{mL}^{-1}$ of cyanidin equivalent. Determinations were performed in triplicate for all samples.

Ellagic acid and gallic acid were quantified in a HPLC (HPLC Agilent 1100 Series, Englewood, CO, USA) with manual injection. $20 \mu \mathrm{L}$ sample loop and ternary pump, coupled to a diode array detector (DAD Agilent G13158). The oven (Agilent 1100) was operated at $25 \pm 2{ }^{\circ} \mathrm{C}$. Data was obtained and processed using the software ChemStation (Hewlett Packard, Germany). A reverse phase chromatographic column (C18 Eclips XDB ( $5 \mu \mathrm{m} \times 250 \mathrm{~mm} \times 4.6 \mathrm{~mm})$, Agilent, Englewood, CO, USA) was used. Mobile phase was $1 \%$ orthophosphoric acid in water $(\mathrm{v} / \mathrm{v})$ (A) and acetonitrile (B). Elution gradient started at 95:05 (A:B) at $0.7 \mathrm{~mL} \mathrm{~min}^{-1}$. This condition was maintained for $5 \mathrm{~min}$ and then concentration of A was decreased (75:25, A:B), and at 25 min it reached $60: 40$ (A:B) followed by a linear increase of solvent A to $95 \%$ until $35 \mathrm{~min}$. Detection was done at 210, 254, 280, 300 and $340 \mathrm{~nm}$, which allowed simultaneous quantification and identification of the phenolic compounds separated by the HPLC. Content of identified compounds were calculated from the analytical curves. The results were expressed as $\mu \mathrm{g} \mathrm{g}^{-1}$ or $\mathrm{mL}^{-1}$. Determinations were performed in triplicate for all samples.

\subsection{Antioxidant assay in vitro}

Antioxidant capacity in FJP MeOH and FJP aqueous extract was determined by DPPH, ABTS ${ }^{+}$, FRAP and ORAC assays. The DPPH (2,2-diphenyl-1-picrylhydrazyl) assay was done according to Brand-Williams, Cuvelier, \& Berset (1995), with some modifications. The decreasing in absorbance of samples and Trolox standard curve was measured after $30 \mathrm{~min}$ of reaction and read at $515 \mathrm{~nm}$. Results were expressed as $\mu \mathrm{M}$ Trolox $\mathrm{g}^{-1}$ or $\mathrm{mL}^{-1}$.

The $\mathrm{ABTS}^{+}$assay was based on the method developed by Miller, Rice-Evans, Davies, Gopinathan, \& Milner (1993), with modifications according to Rufino, Alves, Brito, Pérez-Jiménez, Saura-Calixto, \& Mancini-Filho (2010). The working solution was prepared by reacting $7 \mathrm{mM}$ ABTS (2,2 azinobis (3-ethylbenzothiazoline-6-sulfonic acid) diammoninum salt) stock solution with $140 \mathrm{mM}$ potassium persulfate after $16 \mathrm{~h}$ incubation in the dark at room temperature. The monitored decrease of absorbance over time (30 min with 1 min interval) was plotted and the differences between samples and control were 
calculated. The samples and Trolox standard curve were read at $734 \mathrm{~nm}$. Results were expressed as $\mu \mathrm{M}$ Trolox $\mathrm{g}^{-1}$ or $\mathrm{mL}^{-1}$.

The ferric reducing antioxidant power (FRAP) of samples was determined according to Rufino, Alves, Brito, Pérez-Jiménez, Saura-Calixto, \& Mancini-Filho (2010). The FRAP reagent was prepared in the dark with $300 \mathrm{mmol} \mathrm{L}^{-1}$ acetate buffer (pH 3.6), $10 \mathrm{mmol} \mathrm{L}^{-1} \mathrm{TPTZ}$ (2,4,6-tris(2pyridyl)-S-triazine) in a $40 \mathrm{mmol} \mathrm{L}{ }^{-1} \mathrm{HCl}$ solution and $20 \mathrm{mmol} \mathrm{L}^{-1}$ $\mathrm{FeCl}_{3}$. The samples and Trolox standard curve were read at $595 \mathrm{~nm}$. Results were expressed as $\mu \mathrm{M}$ Trolox $\mathrm{g}^{-1}$ or $\mathrm{mL}^{-1}$.

ORAC assay (oxygen radical absorbance capacity test) was carried out adding $20 \mu \mathrm{L}$ of samples extract or standard solutions, $120 \mu \mathrm{L}$ of fluorescein diluted in phosphate buffer ( $\mathrm{pH} 7.4$ ), and $60 \mu \mathrm{L}$ of AAPH (2,2'-azobis (2-methylpropionamidine) dihydrochloride) to black microplates, in the dark (Dávalos, Gómez-Cordovés, \& Bartolomé, 2004). ORAC values were expressed in $\mu \mathrm{M}$ Trolox $\mathrm{g}^{-1}$ or $\mathrm{mL}^{-1}$. Appropriate calculations were used for check the linearity between the net area under the curve and the concentration for the samples.

The absorbances or fluorescences of these assays were read in a microplate reader SynergyHT, Biotek (Winooski, USA); with Gen $5^{\mathrm{TM}} 2.0$ data analysis software spectrophotometer.

\subsection{Antioxidant assay in vivo}

\subsubsection{Animals and diets}

Thirty-six male Wistar rats, recently weaned, were obtained from the Multidisciplinary Center for Biological Research at Unicamp (CEMIB). The experiment was approved by the Ethics Committee on Animal Experiments (CEUA/UNICAMP), protocol number 32721 , and followed all the ethical requirements of the Brazilian College of Animal Experimentation (COBEA). Animals were maintained in growth period for 4 weeks, feed by commercial pelleted diet. Afterward, animals were randomly distributed into six groups $(n=6)$ and remained at individual cages with food and water under the system of free access, controlled temperature and humidity, with a range of $22 \pm 1{ }^{\circ} \mathrm{C}$ and $60-70 \%$ respectively, and light/dark cycle of $12 \mathrm{~h}$, throughout the experimental period.

Two control diets were given during the experiment: a normal control diet, prepared in accordance with the American Institute of Nutrition (Reeves, Nielsen, \& Fahey, 1993), AIN-93 M, with protein concentration of $12 \%$, lipid concentration of $4 \%$ and $70 \%$ approximately of total carbohydrates and a high-fat fructose control diet, AIN-93 Mmodified with $12 \%$ protein and $35 \%$ of fat, $4 \%$ vegetable oil (soybean) and $31 \%$ of animal origin (lard) and 20\% of fructose (HFF) (Marineli, Moura, Moraes, et al., 2015). The HFF-FJP experimental diet was

Table 1

Composition of modified AIN-93 M diets fed to rats.

\begin{tabular}{|c|c|c|c|}
\hline \multirow[t]{2}{*}{ INGREDIENTS } & AIN-93 M & HFF & HFF-FJP \\
\hline & $\left(\mathrm{g} \mathrm{Kg}^{-1}\right)$ & $\left(\mathrm{g} \mathrm{Kg}^{-1}\right)$ & $\left(\mathrm{g} \mathrm{Kg}^{-1}\right)$ \\
\hline Casein (78\% prot.) & 143.89 & 143.89 & 143.89 \\
\hline Corn starch & 461.69 & 133.18 & 133.18 \\
\hline Maltodextrin & 155.00 & 44.67 & 44.67 \\
\hline Sucrose & 100.00 & 28.82 & 28.82 \\
\hline Soybean oil & 40.00 & 40.00 & 40.00 \\
\hline Cellulose & 50.00 & 50.00 & 50.00 \\
\hline Fructose & - & 200.00 & 200.00 \\
\hline Mineral mix & 35.00 & 35.00 & 35.00 \\
\hline Vitamin mix & 10.00 & 10.00 & 10.00 \\
\hline L-cystine & 1.80 & 1.80 & 1.80 \\
\hline Choline bitartarate & 2.50 & 2.50 & 2.50 \\
\hline Tert-butyl hydroquinone & 0.008 & 0.008 & 0.008 \\
\hline Lard & - & 310.00 & 310.00 \\
\hline FJP powder & - & - & 20.00 \\
\hline Energy value (Kcal g ${ }^{-1}$ ) & 4.17 & 5.45 & 5.51 \\
\hline
\end{tabular}

In the HFF diet, $31 \%$ of lard was added and, consequently, starch, sucrose and maltodextrin contents were reduced. HFF-FJP diet was added of $2 \%$ of freeze-dried jaboticaba peel powder. Value expressed in $\mathrm{Kcal} \mathrm{g}^{-1}$ diet, obtained by calorimetry.

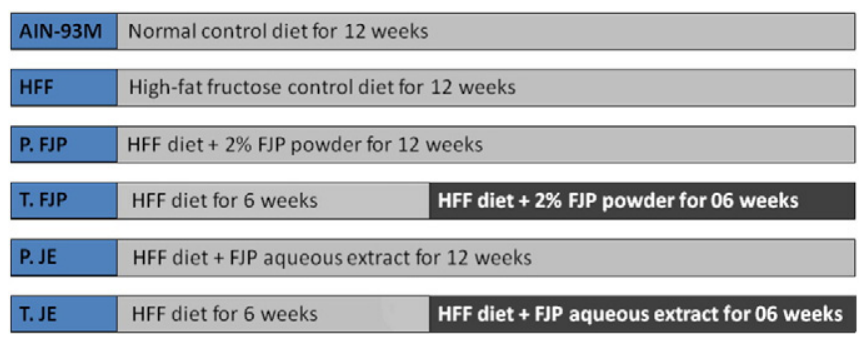

Fig. 1. Experimental design. The animals were maintained on a commercial pelleted diet for 4 weeks for growth. After 4 weeks, they were divided in six groups $(n=6)$ : AIN-93 M (normal control) standard diet; HFF (obese control) received a high-fat and fructose diet containing $4 \%(\mathrm{w} / \mathrm{w})$ soybeanoil, $31 \%(\mathrm{w} / \mathrm{w})$ lard and $20 \%$ fructose (w/w); P. FJP and T. FJP received the HFF diet with $2 \%$ of FJP powder (w/w), for 12 and 6 weeks respectively; P. JE and T. JE received the HFF and had the water substituted by FJP aqueous extract, for 12 and 6 weeks respectively. All diets were based on the AIN-93 M diet.

formulated from high-fat fructose diet adding $2 \%$ of FJP powder. Diets composition is showed in Table 1. The prevention groups (P. FJP and P. $\mathrm{JE}$ ) consumed the supplemented diet or JE for 12 weeks and the treatment groups (T. FJP and T. JE) consumed HFF diet for 6 weeks to induce obesity and started the supplementation as from the sixth week. Groups P. JE and T. JE had the substitution of water by FJP aqueous extract (JE). The experimental design is presented in Fig. 1.

Diet intake was monitored every 2 days and weight gain once a week. The FJP aqueous extract (JE) was prepared daily and its consumption was monitored every day: JE was measured $(25 \mathrm{~mL})$ and placed in animal's bottles, in the next day the JE leftover was measured and the two volumes were recorded. The water consumption of HFF group was monitored to be used as control for the P. JE and T. JE groups.

At 16 experimental weeks, animals were euthanized by decapitation preceded by $12 \mathrm{~h}$ fasting. Blood was collected in tubes with anticoagulant EDTA to obtain plasma. After exsanguination, liver was removed, cleaned with saline solution, weighed, frozen in liquid nitrogen and stored in a freezer at $-80^{\circ} \mathrm{C}$. Frozen liver was divided in aliquots of the $100 \mathrm{mg}$ approximately and the remaining tissue was freeze-dried. The freeze-dried liver was stored in freezer at $-20{ }^{\circ} \mathrm{C}$ for further analysis.

\subsubsection{Lipid peroxidation by thiobarbituric acid reactive substances (TBARS) assay}

TBARS determinations were done in liver and plasma according to Ohkawa, Ohishi, \& Yagi (1979), with adaptations. For liver $10 \mathrm{mg}$ of the freeze-dried tissue were mixed with $1 \mathrm{~mL}$ of acetate buffer $\mathrm{pH} 3.6$ and sonicated for $30 \mathrm{~min}$ in ice bath. The plasma $(100 \mu \mathrm{L})$ was directly pipetted in the tubes by reaction. The $8.1 \%$ sodium dodecyl sulfate (SDS) and working reagent (2-thiobarbituric acid - TBA, 5\% acetic acid and $20 \%$ sodium hydroxide) were added in the samples. After heating at $95{ }^{\circ} \mathrm{C}$ for $60 \mathrm{~min}$, samples remained in ice bath for $10 \mathrm{~min}$ and centrifuged at $14.000 \mathrm{rpm}$ for $10 \mathrm{~min}$. Supernatant was read at $532 \mathrm{~nm}$, using a clear 96-well microplate. Standard curve was obtained using malondialdehyde standard (MDA). Results were expressed in nmol MDA mg tissue ${ }^{-1}$ or nmol $\mathrm{MDA} \mathrm{mL}^{-1}$ plasma.

\subsubsection{Antioxidant potential in liver and plasma by FRAP assay}

FRAP assay was used for determination of the antioxidant capacity in the tissues. Plasma was treated with ethanol, ultrapure water and $0.75 \mathrm{~mol} \mathrm{~L}^{-1}$ metaphosphoric acid (Leite, Malta, Riccio, Eberlin, Pastore, \& Marostica, 2011). Liver homogenate in phosphate buffer (PB) was centrifuged and supernatant was used in FRAP assays (Rufino, Alves, Brito, Pérez-Jiménez, Saura-Calixto, \& Mancini-Filho, 2010) as described above. 


\subsubsection{Enzymatic and non-enzymatic endogenous antioxidant system}

2.7.4.1. Thiol group content (GSH). GSH levels were determined in the PB homogenates of liver and plasma using Ellman's reagent (DTNB) (Ellman, 1959), with modifications. GSH solution (2.5-500 $\mathrm{nmol} \mathrm{GSH} \mathrm{mL}^{-1}$ ) was used as standard and absorbance was read at $412 \mathrm{~nm}$. Reduced thiol contents were expressed in nmol GSH mg protein ${ }^{-1}$.

2.7.4.2. Glutathione peroxidase activity (GPx). GPx activity was quantified in plasma and PB homogenate of liver. The oxidation of $10 \mathrm{mmol}$ reduced glutathione by glutathione peroxidase coupled to the oxidation of $4 \mathrm{mmol}$ NADPH by $1 \mathrm{U}$ enzymatic activity of GR in the presence of $0.25 \mathrm{mmol} \mathrm{H}_{2} \mathrm{O}_{2}$ is measured in this assay. The rate of NADPH oxidation was monitored by the decrease in absorbance at $365 \mathrm{~nm}$ (Flohe \& Gunzler, 1984). Results were expressed in nmol NADPH consumed $\min ^{-1}$ mg protein ${ }^{-1}$.

2.7.4.3. Glutathione reductase activity (GR). GR activity was measured in plasma and in liver PB homogenates, following the decrease in absorbance at $340 \mathrm{~nm}$ induced by $1 \mathrm{mmol}$ oxidized glutathione in the presence of $0.1 \mathrm{mmol}$ NADPH in phosphate buffer (Carlberg \& Mannervik, 1985). Results were expressed in nmol NADPH consumed $\mathrm{min}^{-1} \mathrm{mg}$ protein $^{-1}$.

2.7.4.4. Superoxide dismutase activity. SOD activity was analyzed in liver and plasma. Samples ( $100 \mu \mathrm{L})$ were added in 96-well microplate and $150 \mu \mathrm{L}$ of the working solution $(0.1 \mathrm{mmol}$ hypoxanthine, $0.07 \mathrm{U}$ xanthine oxidase, and $0.6 \mathrm{mmol}$ NTB in PB in 1:1:1 proportions) and the kinetic reaction was monitored at $560 \mathrm{~nm}$ (Winterbourn, Hawkins, Brian, \& Carrell, 1975). Area under the curve (AUC) was calculated and the SOD activity was expressed as $\mathrm{U}$ mg protein $^{-1}$.

2.7.4.5. Catalase activity. Catalase assay is based on reaction of the enzyme with methanol in optimum concentrations of $\mathrm{H}_{2} \mathrm{O}_{2}$. The produced formaldehyde is measured colorimetrically with Purpald (chromophore) (Johansson \& Borg, 1988; Wheeler, Salzman, Elsayed, et al., $1990)$. Liver homogenate and plasma were pipetted $(20 \mu \mathrm{L})$ in 96 -well microplate with $100 \mu \mathrm{L}$ assay buffer, $30 \mu \mathrm{L}$ methanol and $20 \mu \mathrm{L}$ $\mathrm{H}_{2} \mathrm{O}_{2}$. Reaction occurred for $20 \mathrm{~min}$ in shaker of the dark. Thirty $\mu \mathrm{L}$ of potassium hydroxide stop the reaction. Purpald was added $(30 \mu \mathrm{L})$ and the plate was read at $540 \mathrm{~nm}$. The formaldehyde standard curve was done and used for calculate catalase activity. The results were expressed as nmol $\mathrm{min}^{-1} \mathrm{~mL}^{-1}$ or $\mathrm{g}$ protein ${ }^{-1}$.

For FRAP assay, enzymatic and non-enzymatic endogenous antioxidant system analyze in liver, the protein concentration of tissue homogenates was done by Bradford method (Bradford, 1976).

\subsection{Statistical analysis}

Phenolics compounds and antioxidant capacity between the FJP $\mathrm{MeOH}$ extract and FJP aqueous extract were analyzed by Student's $t$-test and the limit of significance was set at $p<0.05$. For biological assays, difference in averages between AIN-93 M and HFF groups was analyzed by Student's $t$-test with limit of significance of 0.05 . Difference between HFF and supplemented groups was analyzed by Analysis of Variance (ANOVA; $\alpha=5 \%$ ) with post hoc Tukey's range test with significant differences between means $(p<0.05)$. Data analyses were carried out with GraphPad Prism 5.0 (GraphPad Software, Inc. La Jolla, CA, USA) software.

\section{Results and discussion}

\subsection{Chemical composition}

The jaboticaba peel is composed mainly of carbohydrates, including soluble and insoluble fiber, and water (Table 2). Possibly, the high
Table 2

Proximate composition of freeze-dried jaboticaba peel.

\begin{tabular}{|c|c|}
\hline NUTRIENTS & $\mathrm{g} 100 \mathrm{~g}^{-1}$ \\
\hline Protein & $7.31 \pm 0.17$ \\
\hline Lipids & $2.71 \pm 0.17$ \\
\hline Moisture & $13.88 \pm 0.08$ \\
\hline Total solids & $86.12 \pm 0.08$ \\
\hline Ashes & $3.84 \pm 0.02$ \\
\hline Soluble fibers & $24.95 \pm 0.15$ \\
\hline Insoluble fibers & $7.88 \pm 0.22$ \\
\hline Carbohydrates & 33.96 \\
\hline Energy value (Kcal g ${ }^{-1}$ ) & $2.55 \pm 0.06$ \\
\hline
\end{tabular}

Data are presented as means \pm standard deviation. The values are expressed as percentage. The carbohydrates were calculated by difference.

content of carbohydrate corresponds the large amount of simple and complex sugars which are the major constituents of fruit peel (Damodaran, Parkin, \& Fennema, 2010). The content of insoluble and soluble fibers, protein and lipids has higher in the present study than in similar studies (Alezandro, Dubé, Desjardins, Lajolo, \& Genovese, 2013a; Alezandro, Granato, \& Genovese, 2013b; Leite, Malta, Riccio, Eberlin, Pastore, \& Marostica, 2011; Lenquiste, Batista, Marineli, et al., 2012). These results in the approximate composition can be justified by harvest time and ripeness of used jaboticaba across studies.

\subsection{Antioxidant assay in vitro}

\subsubsection{Phenolic compounds and antioxidant capacity in FJP extracts}

Jabuticaba peel has a great potential as functional food and as an additive in processed foods (Dessimoni-Pinto, Moreira, Cardoso, \& Pantoja, 2011). On the other hand, jabuticaba peel can be consumed as tea such as formulated in the present study. This proposal becomes practicable once tea is the second most popular beverage in the world. Furthermore, plants infusion contains several flavonoids, substances that are among the polyphenolic compounds, which can have positive biological effects (El-Beshbishy, 2005).

Phenolics compounds and antioxidant capacity in freeze-dried jaboticaba peel (FJP) MeOH extract and FJP aqueous extract are showed in Table 3. Total phenolic compounds, anthocyanins and flavonoids were higher in FJP MeOH extract than in FJP aqueous extract. Total phenolics and anthocyanins in the FJP MeOH extract were similar to those obtained by Alezandro, Dubé, Desjardins, Lajolo, \& Genovese (2013a) and Alezandro, Granato, \& Genovese (2013b), but lower than those obtained by Batista, Lenquiste, Cazarin, et al. (2014).

The gallic acid and cyanidin-3-O-glucoside content were higher in FJP aqueous extract. However, ellagic acid was higher in the FJP $\mathrm{MeOH}$ extract. Gallic acid values showed in FJP MeOH extract was 18\% lower than found by Wu, Dastmalchi, Long, \& Kennelly (2012), which evaluated the phenolic compounds by HPLC in the jaboticaba peel and jaboticaba juice. Nevertheless, in the present study results are in agreement with those demonstrate by Batista, Lenquiste, Cazarin, et al. (2014). Ellagic acid content in FJP MeOH extract was similar to those reported by Abe, Lajolo, \& Genovese (2012) $22.50 \mathrm{~g} \mathrm{Kg}^{-1}$ - and higher than the $348.08 \mathrm{mg} 100 \mathrm{~g}^{-1}$ obtained by Batista, Lenquiste, Cazarin, et al. (2014). In Alezandro, Dubé, Desjardins, Lajolo, \& Genovese (2013a), Alezandro, Granato, \& Genovese (2013b), and Wu, Dastmalchi, Long, \& Kennelly (2012) studies ellagic acid levels were lower than those obtained in this study. Anthocyanin cyanidin-3-O-glucoside in FJP MeOH was higher than those showed by Leite, Malta, Riccio, Eberlin, Pastore, \& Marostica (2011) and Wu, Dastmalchi, Long, \& Kennelly (2012),

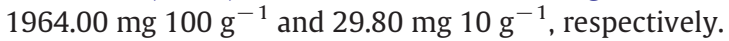

Anthocyanins are more soluble in water and methanol. However, it is known that heating may enhance the extraction of certain 
Table 3

Phenolics compounds and antioxidant capacity in freeze-dried jaboticaba peel (FJP) MeOH extract (g), FJP aqueous extract (g) and FJP aqueous extract (mL).

\begin{tabular}{|c|c|c|c|}
\hline & $\begin{array}{l}\text { FJP MeOH extract } \\
(\mathrm{g})\end{array}$ & $\begin{array}{l}\text { FJP aqueous extract } \\
(\mathrm{g})\end{array}$ & $\begin{array}{l}\text { FJP aqueous extract } \\
(\mathrm{mL})\end{array}$ \\
\hline \multicolumn{4}{|l|}{ Phenolic compounds } \\
\hline Total phenolics & $48.61^{\mathrm{a}} \pm 1.18$ & $36.12^{\mathrm{b}} \pm 3.05$ & $0.72 \pm 0.06$ \\
\hline Anthocyanins & $630.46^{\mathrm{a}} \pm 21.76$ & $404.56^{b} \pm 35.85$ & $8.09 \pm 0.72$ \\
\hline Flavonoids & $7.59^{\mathrm{a}} \pm 0.12$ & $7.22^{\mathrm{b}} \pm 0.02$ & $0.15 \pm 0.01$ \\
\hline \multicolumn{4}{|l|}{ Specific Phenolics } \\
\hline Gallic acid & $36.92^{\mathrm{b}} \pm 2.28$ & $177.76^{\mathrm{a}} \pm 2.26$ & $3.55 \pm 0.05$ \\
\hline Ellagic acid & $3045.44^{\mathrm{a}} \pm 90.97$ & $1581.61^{\mathrm{b}} \pm 135.50$ & $31.63 \pm 2.71$ \\
\hline Cyanidin-3-O-glucoside & $32,945.24^{\mathrm{b}} \pm 347.80$ & $34,242.88^{a} \pm 594.70$ & $685.20 \pm 11.90$ \\
\hline \multicolumn{4}{|l|}{ Antioxidant capacity } \\
\hline DPPH & $346.77^{a} \pm 30.23$ & $320.85^{b} \pm 29.90$ & $6.42 \pm 0.60$ \\
\hline FRAP & $449.68^{a} \pm 18.72$ & $410.65^{a} \pm 10.60$ & $8.21 \pm 0.21$ \\
\hline ABTS & $194.95^{\mathrm{b}} \pm 4.66$ & $223.10^{\mathrm{a}} \pm 2.28$ & $4.46 \pm 0.05$ \\
\hline ORAC & $317.98^{\mathrm{a}} \pm 9.03$ & $213.16^{\mathrm{b}} \pm 15.06$ & $4.26 \pm 0.31$ \\
\hline
\end{tabular}

Data are presented as means \pm standard deviation. Total phenolics are expressed as $\mathrm{mg}$ gallic acid equivalent $\mathrm{g}$ or $\mathrm{mL}^{-1}$. Total flavonoids are expressed as $\mathrm{mg}$ catechin equivalent $\mathrm{g}$ or $\mathrm{mL}^{-1}$. Total anthocyanins are expressed as $\mathrm{mg} 100 \mathrm{~g}$ or mL ${ }^{-1}$. Specific flavonoids are expressed as $\mu \mathrm{g} \mathrm{g} \mathrm{or} \mathrm{mL}{ }^{-1}$. Cyanidin-3-O-glucoside is expressed as $\mu \mathrm{g} g$ or $\mathrm{mL}^{-1}$ of cyanidin equivalent. Antioxidant activities are expressed as $\mu \mathrm{M}$ Trolox $\mathrm{g}$ or $\mathrm{mL}^{-1}$. Statistical differences between FJP MeOH $70 \%$ and FJP aqueous extract are represented by different letters according Student's t-test $(p<0.05)$. The FJP aqueous extract $(\mathrm{mL})$ column was not statistically compared to other columns.

compounds, by breaking hydrogen bonds. Therefore, the concentration of anthocyanins in aqueous extract can be improved by increasing solubility of these compounds through boiling water infusion (Azmir, Zaidul, Rahman, et al., 2013). Daneshfar, Ghaziaskar, \& Homayoun (2008) evaluated the solubility of gallic acid in different solvents such as methanol, ethanol and water and its relationship with temperature. These authors observed that heating increases gallic acid solubility of in water. This may explain the higher concentration of gallic acid in the aqueous extract since it was heated to $95^{\circ} \mathrm{C}$.

Antioxidant capacity of jaboticaba peel extracts was measured by DPPH, FRAP, ABTS and ORAC assays (Table 3). In DPPH and ORAC assays, methanol extract was more efficient than the aqueous extract. The results of FRAP assay were statistically similar for both extracts and the ABTS assay showed higher values in the aqueous extract.

Leite-Legatti, Batista, Dragano, et al. (2012) and Abe, Lajolo, \& Genovese (2012) evaluated the antioxidant capacity by DPPH assay in jaboticaba peel and showed lower values, $45.38 \mu \mathrm{g} \mathrm{mL} \mathrm{m}^{-1}$ and $62.60 \mathrm{mmol} \mathrm{TE} \mathrm{kg}^{-1}$ fresh weight, respectively, than those presented in this study. Otherwise, Alezandro, Dubé, Desjardins, Lajolo, \& Genovese (2013a) and Alezandro, Granato, \& Genovese (2013b) showed higher DPPH value (600.00 TE $100 \mathrm{~g}^{-1}$ ). FRAP assay carried out by Alezandro, Dubé, Desjardins, Lajolo, \& Genovese (2013a), Alezandro, Granato, \& Genovese (2013b), and ABST by Leite-Legatti et al. (2012) showed 68\% and 51\% lower values than those showed in this study. However, ORAC values obtained by Leite-Legatti, Batista, Dragano, et al. (2012) and Batista, Lenquiste, \& Cazarin, et al. (2014) were higher when compared to the present results -

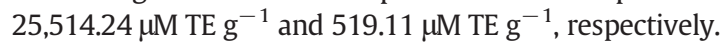

The bioactive compounds in plants, as well as their antioxidant capacity and biological effects, could be an arduous work due to the large content and composition variation that depends of geography, photoperiod and climate. These differences have been reported as influence factors on secondary metabolites biosynthesis such as many flavonoids. Thus, it can affect antioxidant potential range (Jaakola \& Hohtola, 2010; Kumazawa, Hamasaka, \& Nakayama, 2004).

\subsection{Antioxidant capacity in vivo}

\subsubsection{Weight gain and intake parameters}

Weight gain, food intake, energy intake and FJP aqueous extract (JE) intake was showed in Table 4. Daily and cumulative weight gains were higher in the HFF group compared to AIN-93 M. Supplemented groups had lower weight gain than the HFF group. Thus, the HFF diet was able to induce obesity in animals when compared to the AIN-93 M group. Furthermore, FJP and JE supplemented groups were able to counteract this process. Food intake was higher in the AIN-93 M groups than in the HFF group, however energy intake did not differ among groups. There was no difference in JE consumption in P. JE and T. JE groups when compared to water consumption of HFF group.

Studies have been evaluated the effects of purified anthocyanins and fruits rich in these compounds supplementation in high-fat diet on the development of obesity. Jayaprakasam, Olson, Schutzki, Tai, \& Nair

Table 4

Weight gain, food and tea intake.

\begin{tabular}{|c|c|c|c|c|c|c|}
\hline & AIN-93 M & HFF & P. FJP & T. FJP & P. JE & T. JE \\
\hline $\begin{array}{l}\text { Daily weight gain } \\
\quad\left(\mathrm{g} \mathrm{rat} \mathrm{day}^{-1}\right)\end{array}$ & $2.65^{\mathrm{B}} \pm 0.16$ & $3.51^{\mathrm{Aa}} \pm 0.40$ & $3.05^{\mathrm{b}} \pm 0.51$ & $3.09^{b} \pm 0.16$ & $2.77^{b} \pm 0.27$ & $2.65^{\mathrm{b}} \pm 0.37$ \\
\hline $\begin{array}{l}\text { Cumulative weight gain } \\
\left(\mathrm{g} \mathrm{rat}^{-1}\right)\end{array}$ & $226.30^{\mathrm{B}} \pm 15.94$ & $307.90^{\mathrm{Aa}} \pm 25.81$ & $250.41^{\mathrm{b}} \pm 40.38$ & $259.42^{\mathrm{b}} \pm 13.68$ & $233.30^{\mathrm{b}} \pm 23.07$ & $235.40^{\mathrm{b}} \pm 31.83$ \\
\hline $\begin{array}{l}\text { Food intake } \\
\qquad\left(\mathrm{g}^{\text {rat day }}{ }^{-1}\right)\end{array}$ & $23.81^{\mathrm{A}} \pm 1.28$ & $17.49^{\mathrm{Ba}} \pm 1.22$ & $17.54^{\mathrm{a}} \pm 1.12$ & $17.63^{\mathrm{a}} \pm 1.49$ & $16.60^{\mathrm{a}} \pm 1.35$ & $16.14^{\mathrm{a}} \pm 1.10$ \\
\hline Energy intake (Kcal rat day ${ }^{-1}$ ) & $91.94^{\mathrm{B}} \pm 4.31$ & $95.71^{\mathrm{Aa}} \pm 4.02$ & $97.20^{\mathrm{a}} \pm 8.18$ & $96.10^{a} \pm 5.56$ & $91.15^{\mathrm{a}} \pm 7.39$ & $89.98^{\mathrm{a}} \pm 4.71$ \\
\hline $\begin{array}{l}\text { Water or JE intake } \\
\left(\mathrm{mL} \mathrm{rat} \mathrm{day}^{-1}\right)\end{array}$ & - & $18.18^{\mathrm{a}} \pm 2.90$ & - & - & $17.98^{\mathrm{a}} \pm 2.68$ & $15.97^{\mathrm{a}} \pm 1.38$ \\
\hline
\end{tabular}

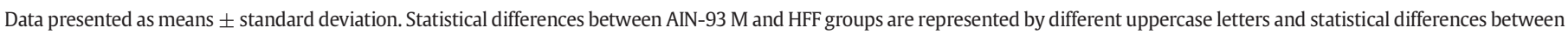

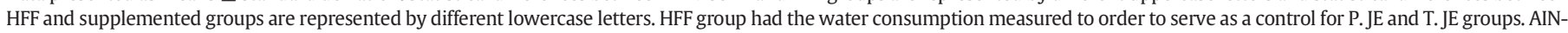

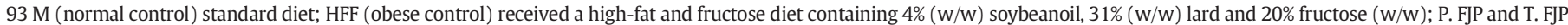

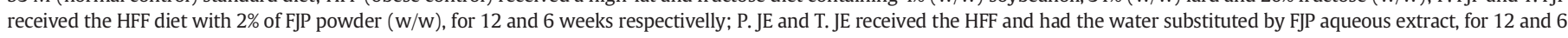
weeks respectivelly. 
(2006) and Prior, Wu, Gu, Hager, Hager, \& Howard (2008) showed that the supplementation of different sources of cyanidin-3-O-glucoside (C3G) extracted in a high-fat diets reduced mice weight gain. However, the consumption of freeze-dried foods as a source of anthocyanins added to high-fat diet has not shown effects on weight gain neither in body fat in animal models (Batista, Lenquiste, Cazarin, et al., 2014; DeFuria, Bennett, Strissel, et al., 2009; Dragano, Marques, Cintra, et al., 2013; Lenquiste, Batista, Marineli, et al., 2012; Prior, Wilkes, Rogers, Khanal, Wu, \& Howard, 2010).

The effects of phenolic compounds on obesity have been studied and its effect on weight gain and body mass are still divergent. Nevertheless, acceptable mechanisms for antiobesogenic potential of these compounds have been proposed. Alezandro, Granato, \& Genovese (2013b) demonstrated significant inhibitory activity of $\alpha$-amylase and $\alpha$ glucosidase enzymes in induced diabetic rats fed with jaboticaba peel. Sergent, Vanderstraeten, Winand, Beguin, \& Schneider (2012) showed that phenolic compounds of green tea inhibited pancreatic lipase activity which delayed or decreased in vivo fatty acid absorption by enterocytes. Thus, the enzymatic inhibition can be a mechanism in the obesity regulation. In recent study, Dragano, Marques, Cintra, et al. (2013) reported that despite the consumption of FJP added to the high-fat did not effected on mice weight gain, insulin resistance and modulated proteins associated with obesity, inflammation and diabetes were improved.

\subsubsection{Antioxidant potential and lipid peroxidation}

Bioactive compounds have been studied due to their effects on preventing damage caused by ROS and free radicals which are widely produced during metabolic processes. In order to reduce oxidative stress, the organisms have developed mechanisms. These mechanisms include the non-enzymatic and enzymatic antioxidant defenses produced in endogenously and others provided by diet (exogenous) (Han, Shen, \& Lou, 2007).

There were no difference in plasma and liver FRAP assay (Fig. 2A, B). Leite, Malta, Riccio, Eberlin, Pastore, \& Marostica (2011) evaluated plasma antioxidant capacity by ABTS assay after FJP diet supplementation.
They reported that the addition of 1 and 2\% de FJP powder in a normolipidic diet increased the antioxidant potential. However at $4 \%$ FJP powder diet it showed an inverse effect. Additionally, Batista, Lenquiste, Cazarin, et al. (2014) evaluated the antioxidant potential in several organs of rats which consumed HF diet supplemented with FJP at 1,2 and $4 \%$. These authors observed that in plasma samples TEAC assay showed higher values in animals fed with 2 and $4 \%$ of FJP. Nevertheless, ORAC and FRAP assay did not differ among groups. In liver samples, they showed that ORAC assay was higher in the FJP supplemented groups compared to HF group, but TEAC and FRAP assay did not differ among groups. FRAP assay was used by Alezandro, Granato, \& Genovese (2013b) to evaluated oxidative stress in streptozotocinmediated diabetic rats. In this study, plasma antioxidant capacity of diabetic rats was increased ( 2 to 2.5 times) after both jaboticaba doses (1.0 and $2.0 \mathrm{~g}$ dry weight $\mathrm{kg}^{-1}$ body weight) supplementation for 40 days.

Lipid peroxidation in plasma and liver was measured by TBARS assay. HFF group showed higher MDA level in plasma and liver than AIN-93 M, showing increased lipid peroxidation. This damaging process was reversed by FJP and JE supplementation (Fig. 2C, D). Wu, Ma, Li, Deng, Yin, \& Huang (2015) evaluated serum MDA levels in mice fed with normal or three types of flavonoids extracts in supplemented diets. They observed that the extracts groups had lower MDA level than the control groups. Several studies has also shown positive effects of foods rich in phenolic compounds on lipid peroxidation (Alezandro, Granato, \& Genovese, 2013b; Batista, Lenquiste, Cazarin, et al., 2014; Silva, Souza, Thomazini, et al., 2014). Thus, MDA levels are an important marker of lipid peroxidation and can be modulated by phenolic compounds intake.

\subsubsection{Thiol group content and antioxidant enzymes}

The increased oxidative stress is related to an overproduction of free radicals or deficiency in the antioxidant defense system (Habib \& Ibrahim, 2011). Plasma GPx and GR did not differ among groups (Fig. 3A, B). However, plasma GSH level was significantly lower in HFF group compared to the AIN-93 M group. FJP and JE supplemented
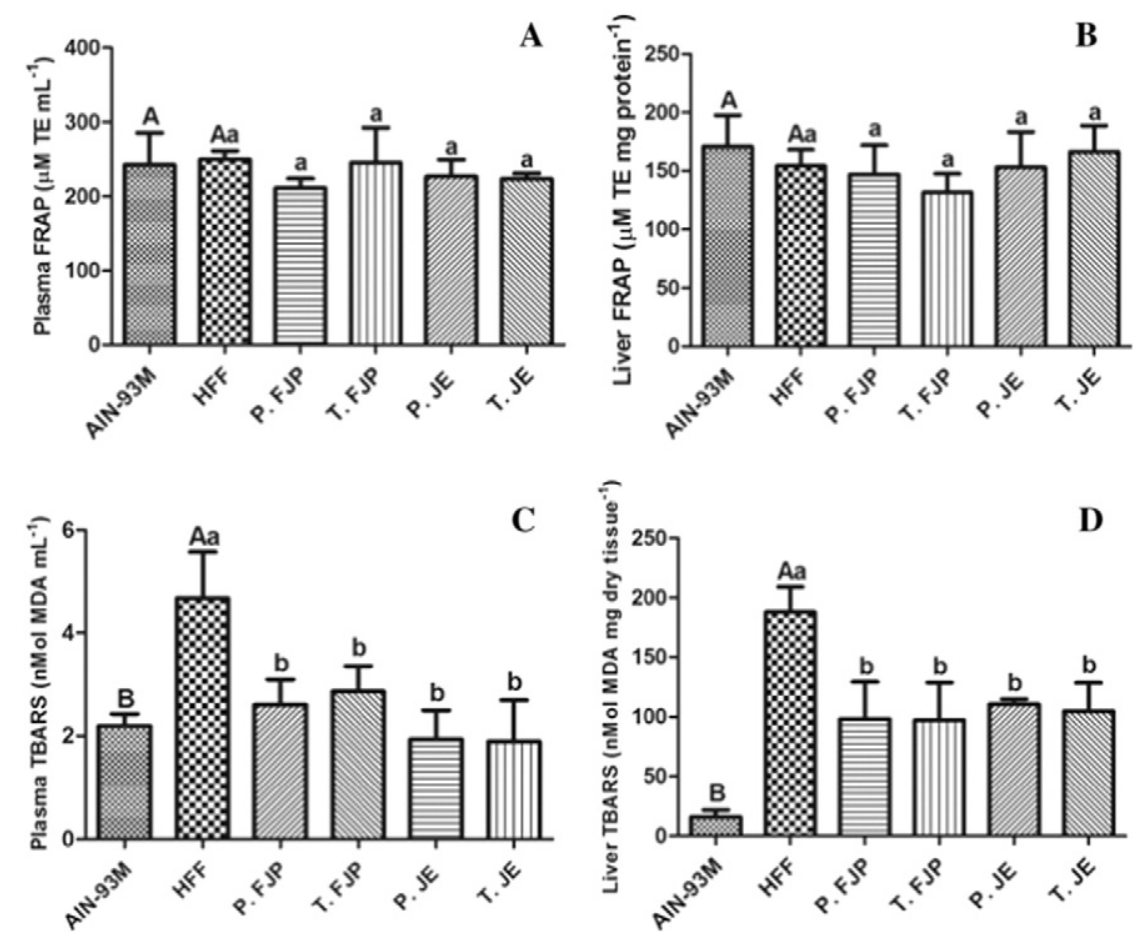

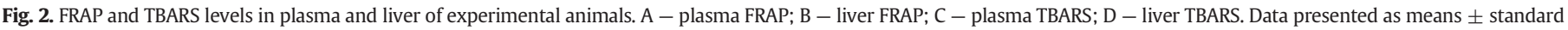

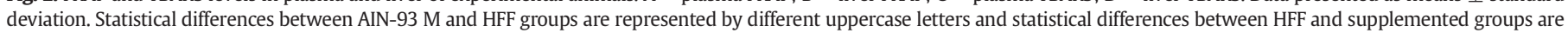
represented by different lowercase letters. 

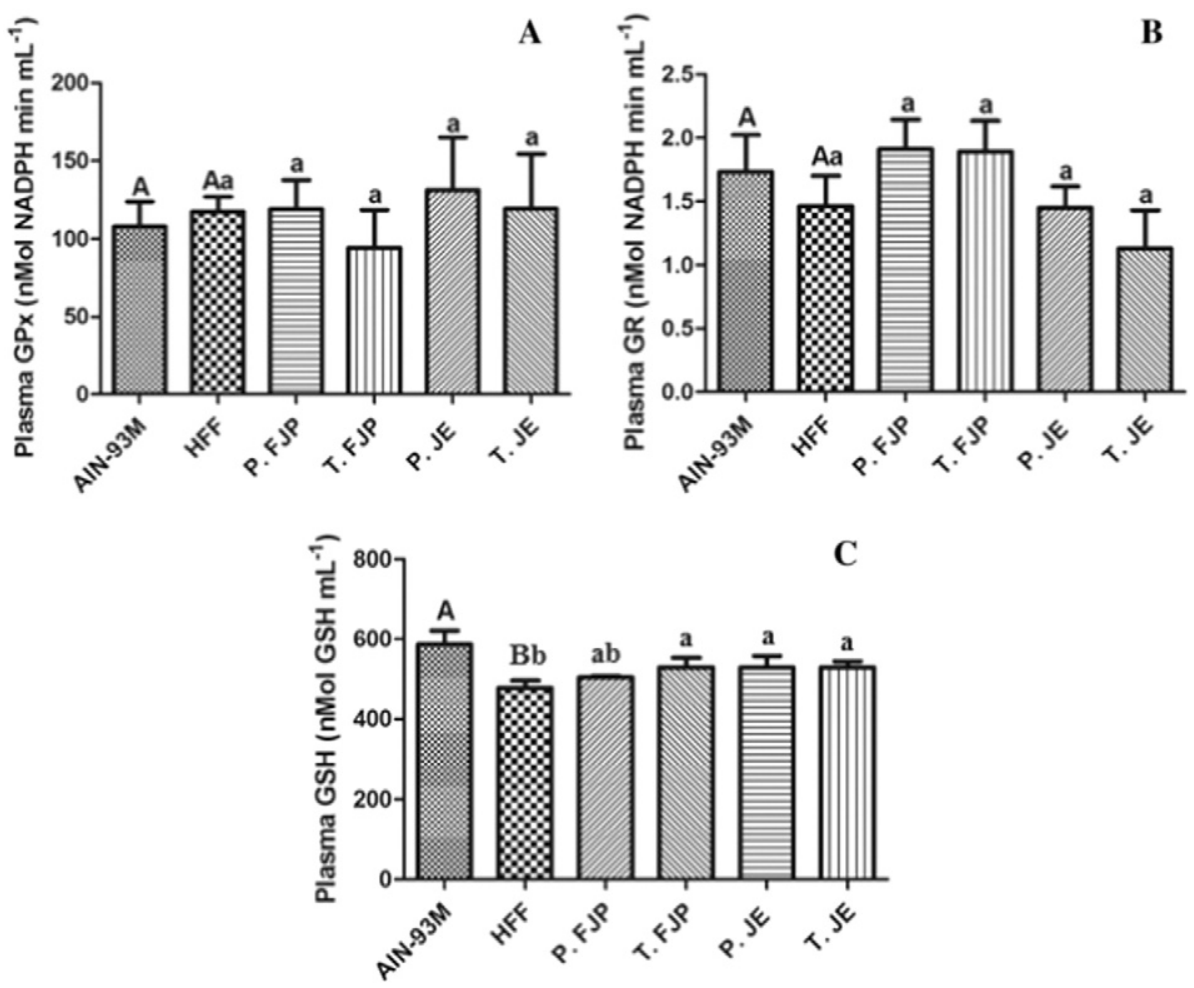

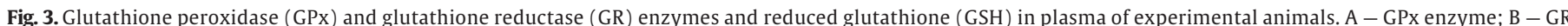

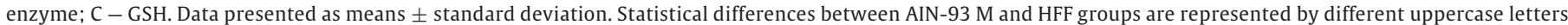
and statistical differences between HFF and supplemented groups are represented by different lowercase letters.

groups showed an increase in this biomarker compared to HFF group (Fig. 3C). In liver, GPx level was higher in AIN-93 M group compared to HFF group and there was no difference among HFF and supplemented groups (Fig. 4A). Liver GR level was lower in AIN-93 M group compared to HFF group. Supplements FJP and JE did not reduce the GR level compared to HFF group (Fig. 4B). Liver GSH level was lower in HFF group
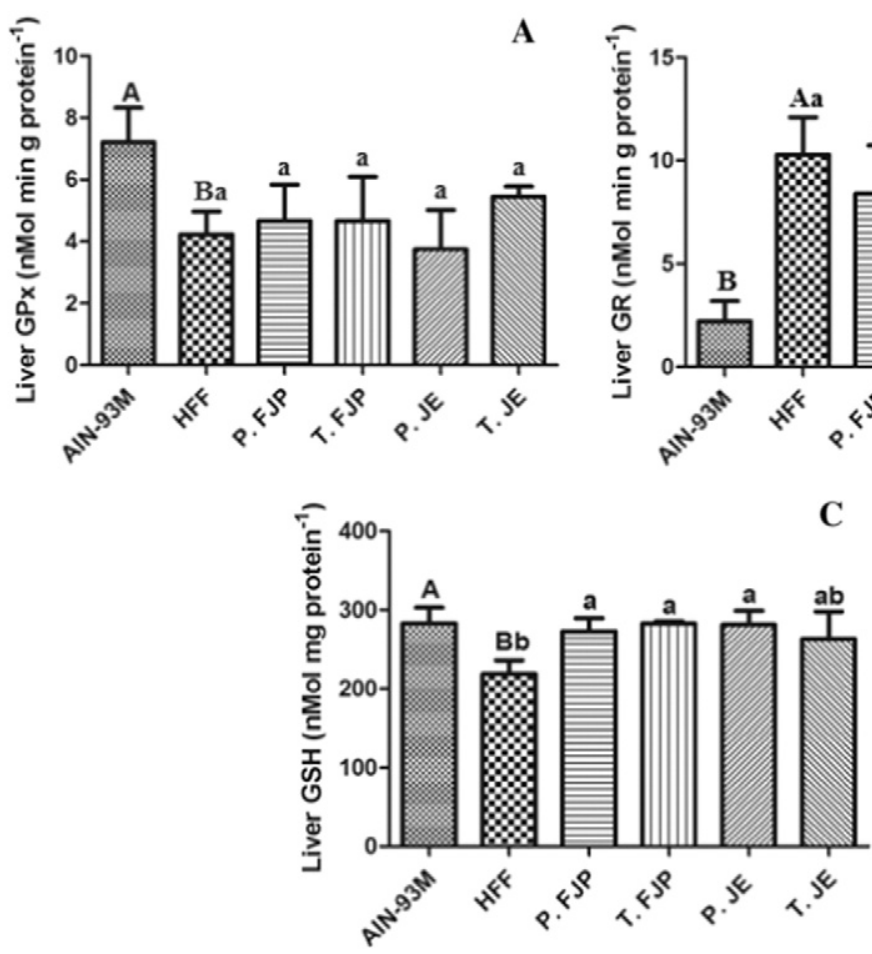

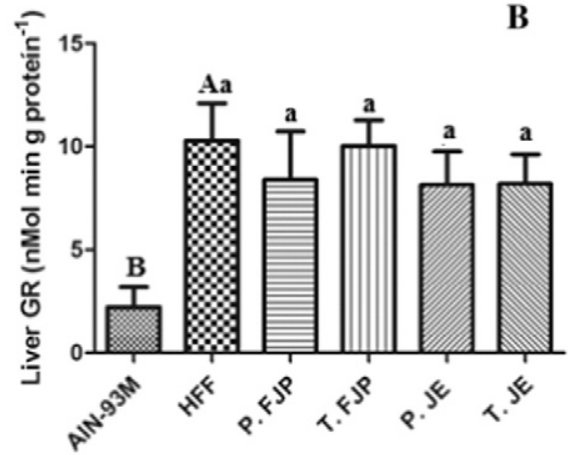

C

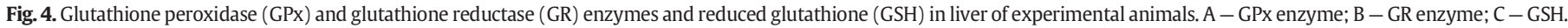

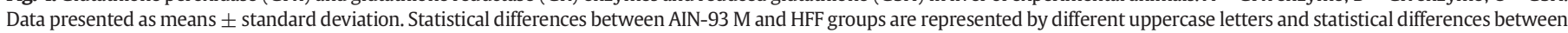
HFF and supplemented groups are represented by different lowercase letters. 

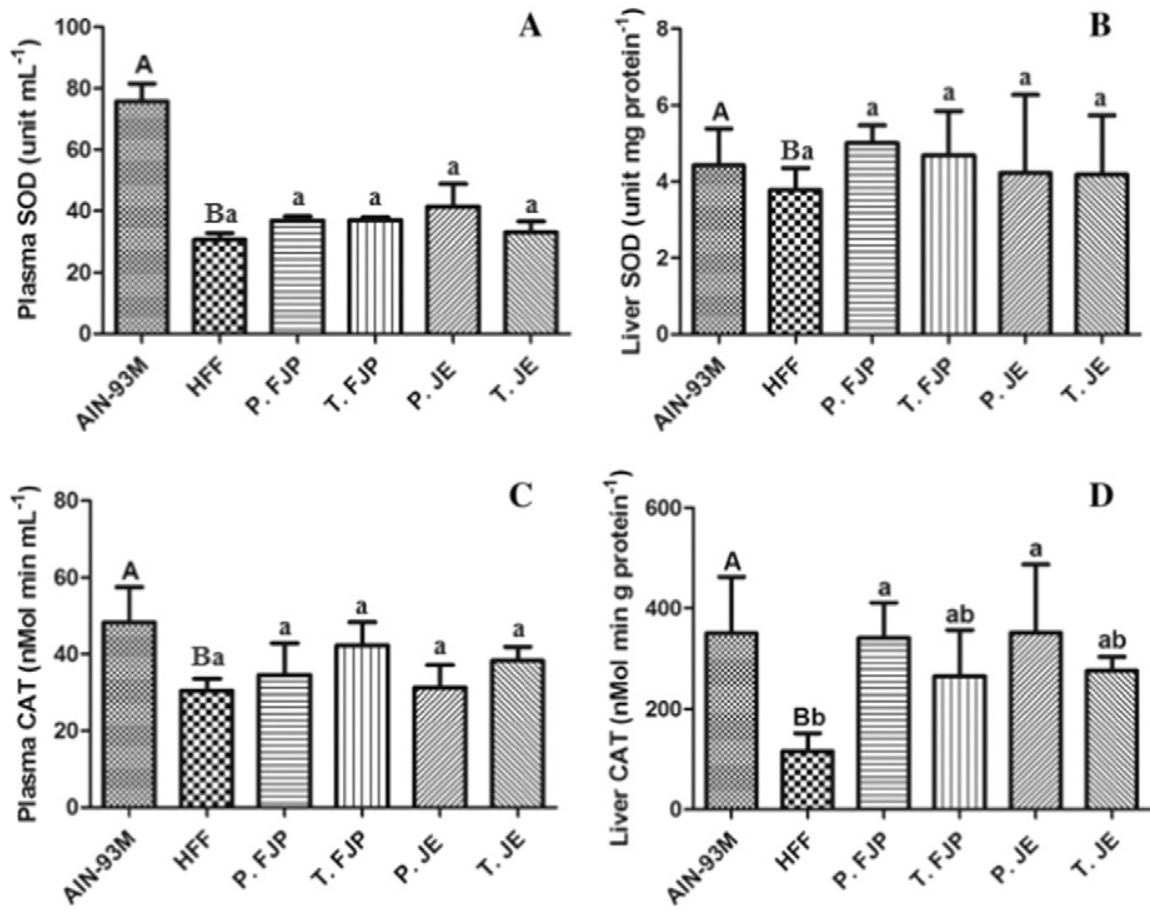

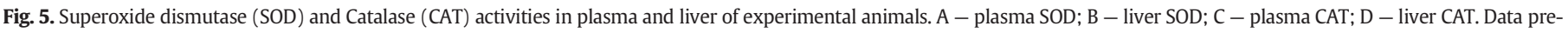

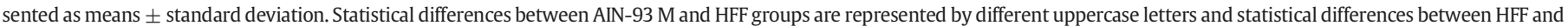
supplemented groups are represented by different lowercase letters.

compared to AIN-93 M. FJP and JE groups showed an increase in this biomarker compared to HFF group (Fig. 4C). Thus, only plasma and liver GSH levels were positively modulated by FJP and JE intake.

Plasma and liver SOD activity was significantly lower in HFF group compared to AIN-93 M group. There was no significant difference in plasma and liver SOD activities among HFF and supplemented groups (Fig. 5A, B). There was no plasma significant difference in CAT activity among groups (Fig. 5C). Liver CAT level was lower in HFF group than in AIN-93 M group. The P. FJP and P. JE groups showed higher CAT activity than HFF group, whereas T. FJP and T. JE groups showed an increase in CAT activity. However, these values were not statistically different compared to HFF group (Fig. 5D). Thus, FJP and JE supplementation for 12 weeks increased CAT levels in animal's liver.

Glutathione is the main source of reducing power. It is maintained in reduced form of GR, which acts with NADPH. Therefore, increasing or maintaining of total GSH level added up an improvement of GR level could be an important indicator of antioxidant system enhancement (Skrzydlewska, Ostrowska, Farbiszewski, \& Michalak, 2002). Wu, Ma, Li, Deng, Yin, \& Huang (2015) showed an increasing in GPx and SOD activity in mice plasma supplemented with extract rich in flavonoids. Antioxidant enzymes were measured in plasma and liver of diet-induced obese rats after FJP supplementation. It was shown that the FJP promoted an increase in plasma SOD and CAT, as well as liver SOD, CAT and GPX levels (Batista, Lenquiste, Cazarin, et al., 2014). Similar results were obtained by Alezandro, Granato, \& Genovese (2013b). They showed an increase of antioxidant enzymes in plasma, kidneys, brain and liver in diabetic rats supplemented with FJP extract by gavage.

In vivo studies have been evaluated the supplementation effects of foods rich in phenolics compounds on antioxidant enzymes activity (Han, Matsumoto, Shimada, Sekikawa, \& Fukushima, 2007; Han, Shen, \& Lou, 2007; Suwannaphet, Meeprom, Yibchok-Anun, \& Adisakwattana, 2010; Tedesco, Luigi, Nazzaro, Russo, \& Palumbo, 2001). Scientific evidence has shown that these compounds, especially anthocyanins, can have a powerful antioxidant effect, in vitro and in vivo studies (Alezandro, Granato, \& Genovese, 2013b; Batista, Lenquiste, Cazarin, et al., 2014; Habib \& Ibrahim, 2011). However, the results are still inconsistent and studies focused in possible mechanisms of action are needed.

\section{Conclusion}

Jaboticaba peel is a good source of bioactive compounds. FJP could have an excellent application as a food additive. Furthermore, FJP aqueous extract can be consumed as a tea which could provide an alternative bioactive compound source for human consumption. FJP and FJP aqueous extract had a higher antioxidant potential in vitro. The in vivo antioxidant potential of FJP and JE was confirmed by remarkable biomarkers, such as TBARS and GSH levels and CAT activity, but did not by FRAP assay, and SOD, GR and GPx enzymes. Thus, further studies are necessary in order to confirm the in vivo effects of the FJP and JE.

\section{Acknowledgments}

We thank Conselho Nacional de Desenvolvimento Científico e Tecnológico (CNPq) for financial support. MRMJ acknowledges CNPq for financial support (300533/2013-6).

\section{References}

Abe, L.T., Lajolo, F.M., \& Genovese, M.I. (2012). Potential dietary sources of ellagic acid and other antioxidants among fruits consumed in Brazil: Jabuticaba (Myrciaria jaboticaba (Vell.) Berg). Journal of the Science of Food and Agriculture, 92, 1679-1687.

Alezandro, M.R., Dubé, P., Desjardins, Y., Lajolo, F.M., \& Genovese, M.I. (2013a). Comparative analysis of chemical and phenolic composition of two species of jaboticaba: Myrciaria jaboticaba (Vell.) Berg and Myrciaria cauliflora (Mart.) 0. Berg. Food Research International, 54, 468-477.

Alezandro, M.R., Granato, D., \& Genovese, M.I. (2013b). Jaboticaba (Myrciaria jaboticaba (Vell.) Berg), a Brazilian grape-like fruit, improves plasma lipid profile in streptozotocin-mediated oxidative stress in diabetic rats. Food Research International, 54, 650-659.

Ando, K., \& Fujita, T. (2009). Metabolic syndrome and oxidative stress. Free Radical Biology and Medicine, 47, 213-218. 
Aschbachera, K., Kornfeldc, S., Picardd, M., et al. (2014). Chronic stress increases vulnerability to diet-related abdominal fat, oxidative stress, and metabolic risk. Psychoneuroendocrinology, 46, 14-22.

Asp, N., Johansson, C., Hallmer, H., \& Siljestrom, M. (1983). Rapid enzimatic assay of insoluble and soluble dietary fiber. Journal of Agricultural and Food Chemistry, 31, 476-482.

Association of Official Analytical Chemists - AOAC (2002). Official methods of analysis of AOAC international. Arlington Virginia: Patricia Cunniff.

Azmir, J., Zaidul, I.S.M., Rahman, M.M., et al. (2013). Techniques for extraction of bioactive compounds from plant materials: A review. Journal of Food Engineering, 117, 426-436.

Batista, A.G., Lenquiste, S.A., Cazarin, C.B.B., et al. (2014). Intake of jaboticaba peel attenuates oxidative stress in tissues and reduces circulating saturated lipids of rats with high-fat diet-induced obesity. Journal of Functional Foods, 6, 450-461.

Bligh, E.G., \& Dyer, W.J. (1959). A rapid method of total lipid extration and purification. Canadian Journal of Biochemistry and Physiology, 37, 911-917.

Bradford, M.M. (1976). A rapid and sensitive method for the quantitation of microgram quantities of protein utilizing the principle of protein-dye binding. Analytical Biochemistry, 72, 248-254.

Brand-Williams, W., Cuvelier, M.E., \& Berset, C. (1995). Use of a free radical method to evaluate antioxidant activity. LWT - Food Science and Technology, 28(1), 25-30.

Carlberg, I., \& Mannervik, B. (1985). Glutathione-reductase. Methods in Enzymology, 113, 484-490.

Damodaran, S., Parkin, K.L., \& Fennema, O.R. (2010). Fisiologia pós-colheita de tecidos vegetais comestíveis. In J.K. Brecht, M.A. Ritenour, N.F. Haard, \& G.W. Chism (Eds.), Química de Alimentos de Fennema (pp. 759-818). Porto Alegre, Brasil: Artmed.

Daneshfar, A., Ghaziaskar, H.S., \& Homayoun, N. (2008). Solubility of gallic acid in methanol, ethanol, water, and ethyl acetate. Journal of Chemical \&' Engineering Data, 53(3), 776-778.

Dávalos, A., Gómez-Cordovés, C., \& Bartolomé, B. (2004). Extending applicability of the oxygen radical absorbance capacity (ORAC - Fluorescein) assay. Journal of Agricultural and Food Chemistry, 52(1), 48-54.

DeFuria, J., Bennett, G., Strissel, K.J., et al. (2009). Dietary blueberry attenuates wholebody insulin resistance in high-fat-fed mice by reducing adipocyte death and its inflammatory sequelae. Journal of Nutrition, 139, 1510-1516.

Dessimoni-Pinto, N.A.V., Moreira, W.A., Cardoso, L.M., \& Pantoja, L.A. (2011). Jaboticaba peel for jelly preparation: An alternative technology. Ciência e Tecnologia de Alimentos, 31(4), 864-869.

Dragano, N.R.V., Marques, A.C., Cintra, D.E.C., et al. (2013). Freeze-dried jaboticaba peel powder improves insulin sensitivity in high-fat-fed mice. British Journal of Nutrition, $110,447-455$.

Durackova, Z. (2010). Some current insights into oxidative stress. Physiological Research, 59(4), 459-469.

El-Beshbishy, H.A. (2005). Hepatoprotective effect of green tea (Camellia sinensis) extract against tamoxifen-induced liver injury in rats. Journal of Biochemistry and Molecular Biology, 38(5), 563-570.

Ellman, G.L. (1959). Tissue sulfhydryl groups. Archives of Biochemistry and Biophysics, 82(1), 70-77.

Feillet-Coudray, C., Sutra, T., Fouret, G., et al. (2009). Oxidative stress in rats fed a high-fat high-sucrose diet and preventive effect of polyphenols: involvement of mitochondrial and NAD(P)H oxidase systems. Free Radical Biology and Medicine, 46, 624-632.

Flohe, L., \& Gunzler, W.A. (1984). Assays of glutathione-peroxidase. Methods in Enzymology, 105, 114-121.

Fuleki, T., \& Francis, F.J. (1968). Quantitative methods for anthocyanins. Journal of Food Science, 33(1), 72-77.

Habib, H.M., \& Ibrahim, W.H. (2011). Effect of date seeds on oxidative damage and antioxidant status in vivo. Journal of the Science of Food and Agriculture, 91(9), 1674-1679.

Han, K.H., Matsumoto, A., Shimada, K., Sekikawa, M., \& Fukushima, M. (2007a). Effects of anthocyanin-rich purple potato flakes on antioxidant status in F344 rats fed a cholesterol-rich diet. British Journal of Nutrition, 98, 914-921.

Han, X., Shen, T., \& Lou, H. (2007b). Dietary polyphenols and their biological significance. International Journal of Molecular Sciences, 8, 950-988.

Herald, T.J., Gadgil, P., \& Tilley, M. (2012). High-throughput micro plate assays for screening flavonoid content and DPPH-scavenging activity in sorghum bran and flour. Journal of the Science of Food and Agriculture, 92(11), 2326-2331.

Jaakola, L., \& Hohtola, A. (2010). Effect of latitude on flavonoid biosynthesis in plants. Plant, Cell \& Environment, 33(8), 1239-1247.

Jayaprakasam, B., Olson, L.K., Schutzki, R.E., Tai, M.H., \& Nair, M.G. (2006). Amelioration of obesity and glucose intolerance in highfat-fed C57BL/6 mice by anthocyanins and ursolic acid in cornelian cherry (Cornus mas). Journal of Agricultural and Food Chemistry, 54, 243-248.

Johansson, L.H., \& Borg, L.A.H. (1988). A spectrophotometric method for determination of catalase activity in small tissue samples. Analytical Biochemistry, 174(1), 331-336.

Kumazawa, S., Hamasaka, T., \& Nakayama, T. (2004). Antioxidant activity of propolis of various geographic origins. Food Chemistry, 84(3), 329-339.

Leite, A.V., Malta, L.G., Riccio, M.F., Eberlin, M.N., Pastore, G.M., \& Marostica, M.R. (2011). Antioxidant potential of rat plasma by administration of freeze-dried Jaboticaba peel (Myrciaria jaboticaba Vell Berg). Journal of Agricultural and Food Chemistry, 59(6), 2277-2283.

Leite-Legatti, A.V., Batista, A.G., Dragano, N.R.V., et al. (2012). Jaboticaba peel: Antioxidant compounds, antiproliferative and antimutagenic activities. Food Research International, 49, 596-603.

Lenquiste, S.A., Batista, A.G., Marineli, R.S., et al. (2012). Freeze-dried jaboticaba pee added to high-fat diet increases HDL-cholesterol and improves insulin resistance in obese rats. Food Research International, 49, 153-160.

Lima, A.J.B., Duarte, C.A., Carvalho, A.A.P., Patto, A.C.M., \& Dantas-Barros, A.M. (2008) Chemical characterization of the jabuticaba fruits (Myrciaria cauliflora Berg) and their fractions. Archivos Latinoamericanos de Nutrición, 58, 416-421.

Lin, L.Z., \& Harnly, J. (2007). A standardized method for the identification of glycosylated flavonoids and other phenolic compounds in all plant materials. Journal of Agricultura and Food Chemistry, 55, 1084-1096.

Marineli, R.S., Moura, C.S., Moraes, E.A., et al. (2015). Chia (Salvia hispanica L.) enhances HSP, PGC-1a expressions and improves glucose tolerance in diet-induced obese rats. Nutrition, 31, 740-748

Miller, N.J., Rice-Evans, C., Davies, M.J., Gopinathan, V., \& Milner, A. (1993). A novel method for measuring antioxidant capacity and its application to monitoring the antioxidant status in premature neonates. Clinical Science, 84(4), 407-412.

Ohkawa, H., Ohishi, N., \& Yagi, K. (1979). Assay for lipid peroxides in animal-tissues by thiobarbituric acid reaction. Analytical Biochemistry, 95(2), 351-358.

Prior, R.L., Wilkes, E.S., Rogers, R.T., Khanal, R.C., Wu, X., \& Howard, L.R. (2010). Purified blueberry anthocyanins and blueberry juice alter development of obesity in mice fed an obesogenic high-fat diet. Journal of Agricultural and Food Chemistry, 58 3970-3976.

Prior, R.L., Wu, X., Gu, L., Hager, T.J., Hager, A., \& Howard, L.R. (2008). Whole berries versus Berry anthocyanins: Interactions with dietary fat levels in the C57BL/6J mouse model of obesity. Journal of Agricultural and Food Chemistry, 56, 647-653.

Reeves, P.G., Nielsen, F.H., \& Fahey, G.C., Jr. (1993). AIN-93 purified diets for laboratory rodents: Final report of the American Institute of Nutrition Ad Hoc Writing Committee on the Reformulation of the AIN-76A rodent diet. Journal of Nutrition, 123, 1939-1951.

Rezaie, A., Parker, R.D., \& Abdollahi, M. (2007). Oxidative stress and pathogenesis of inflammatory bowel disease: An epiphenomenon or the cause? Digestive Diseases and Sciences, 52(9), 2015-2021.

Rufino, M. S. M., Alves, R.E., Brito, E.S., Pérez-Jiménez, J., Saura-Calixto, F., \& Mancini-Filho, J. (2010). Bioactive compounds and antioxidant capacities of 18 non-traditional tropical fruits from Brazil. Food Chemistry, 121(4), 996-1002.

Sergent, T., Vanderstraeten, J., Winand, J., Beguin, P., \& Schneider, Y. (2012). Phenolic compounds and plant extracts as potential natural anti-obesity substances. Food Chemistry, 135(1), 68-73.

Silva, M.C., Souza, V.B., Thomazini, M., et al. (2014). Use of the jabuticaba (Myrciaria cauliflora) depulping residue to produce a natural pigment powder with functional properties. LWT - Food Science and Technology, 55, 203-209.

Singleton, V.L., Orthofer, R., \& Lamuela-Raventos, R.M. (1999). Analysis of total phenolsand other oxidation substrates and antioxidants by means of FolinCiocalteu reagent. Methods in Enzymology, 299, 152-178.

Skrzydlewska, E., Ostrowska, J., Farbiszewski, R., \& Michalak, K. (2002). Protective effect of green tea against lipid peroxidation in the rat liver, blood serum and the brain. Phytomedicine, 9(3), 232-238.

Suwannaphet, W., Meeprom, A., Yibchok-Anun, S., \& Adisakwattana, S. (2010). Preventive effect of grape seed extract against high-fructose diet-induced insulin resistance and oxidative stress in rats. Food and Chemical Toxicology, 48, 1853-1857.

Tedesco, I., Luigi, R.G., Nazzaro, F., Russo, M., \& Palumbo, R. (2001). Antioxidant effect of red wine anthocyanins in normal and catalase-inactive human erythrocytes. Journal of Nutritional Biochemistry, 12, 505-511.

Tsuchiya, H., Ebataa, Y., Sakabeb, T., Hamaa, S., Kogurea, K., \& Shiota, G. (2013). High-fat, high-fructose diet induces hepatic iron overload via a hepcidin-independent mechanism prior to the onset of liver steatosis and insulin resistance in mice. Metabolism, Clinical and Experimental, 62, 62-69.

Wheeler, C.R., Salzman, J.A., Elsayed, N.M., et al. (1990). Automated assays for superoxide dismutase, catalase, glutathione peroxidase, and glutathione reductase activity Analytical Biochemistry, 184(2), 193-199.

Winterbourn, C.C., Hawkins, R.E., Brian, M., \& Carrell, R.W. (1975). Estimation of red-cel superoxide-dismutase activity. The Journal of Laboratory and Clinical Medicine, 85(2), 337-341.

Wu, S., Dastmalchi, K., Long, C., \& Kennelly, E.J. (2012). Metabolite profiling of jaboticaba (Myrciaria cauliflora) and other dark-colored fruit juices. Journal of Agricultural and Food Chemistry, 60, 7513-7525.

Wu, S., Long, C., \& Kennelly, E.J. (2013). Phytochemistry and health benefits of jaboticaba, an emerging fruit crop from Brazil. Food Research International, 54, 148-159.

Wu, P., Ma, G., Li, N., Deng, Q., Yin, Y., \& Huang, R. (2015). Investigation of in vitro and in vivo antioxidant activities of flavonoids rich extract from the berries of Rhodomyrtus tomentosa (Ait.) Hassk. Food Chemistry, 173, 194-202. 